\title{
Experimental and model studies of various size water droplet impacting on a hydrophobic surface
}

\author{
Abba Abubakar ${ }^{1}$, Bekir Yilbas ${ }^{2}$, Hussain Al-Qahtani ${ }^{1}$, Ghassan Hassan ${ }^{1}$, Mubarak \\ Takubu $^{1}$, Saeed Bahattab ${ }^{1}$, and Johhn Adukwu ${ }^{1}$ \\ ${ }^{1}$ King Fahd University of Petroleum \& Minerals \\ ${ }^{2}$ Professor
}

May 5, 2020

\begin{abstract}
Droplet impact on a hydrophobic surface is considered and the influence of the droplet volume on the impact characteristics is analyzed. Pressure variation and the characteristics of the droplet in the spreading and retraction cycles are numerically predicted incorporating the conditions adopted in the experiments. The dynamics of the impacting droplet on the hydrophobic surface is simulated and the impacting droplet motion is recorded using the high speed recording system. It is found that the numerical predictions of the impacting droplet shape and height ratios during the spreading and the contraction cycles are in good agreement with those of the experimental data. Increasing droplet volume increases: i) the peak pressure in the droplet fluid upon the impact and ii) the transition period of the droplet on the hydrophobic surface. Increasing droplet volume enhances peak velocity of the droplet spreading on the surface.
\end{abstract}

\section{Hosted file}

AIChe Paper.docx available at https://authorea.com/users/302303/articles/432500-experimentaland-model-studies-of-various-size-water-droplet-impacting-on-a-hydrophobic-surface 

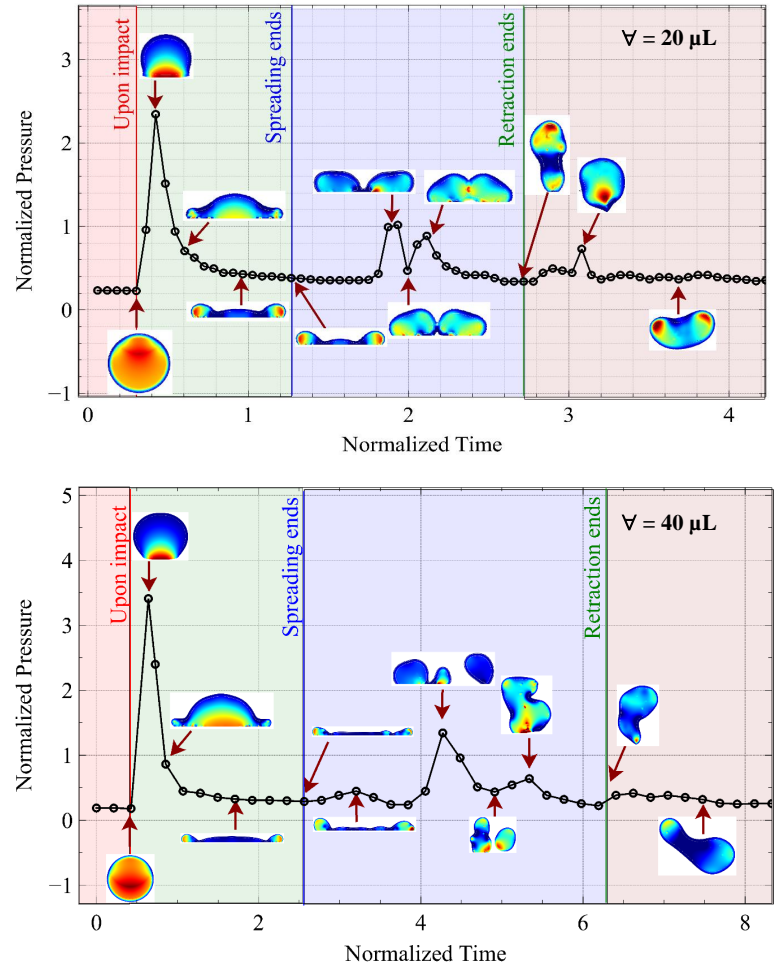